\title{
BMG Global Heath Media bias exposure and the incidence of COVID-19 in the USA
}

\author{
Jonathan Spiteri
}

\begin{abstract}
To cite: Spiteri J. Media bias exposure and the incidence of COVID-19 in the USA. BMJ Global Health 2021;6:e006798. doi:10.1136/ bmjgh-2021-006798
\end{abstract}

Handling editor Seye Abimbola

- Additional supplemental material is published online only. To view, please visit the journal online (http://dx.doi.org/10. 1136/bmjgh-2021-006798).

Received 2 July 2021 Accepted 27 August 2021

\section{Check for updates}

(c) Author(s) (or their employer(s)) 2021. Re-use permitted under CC BY-NC. No commercial re-use. See rights and permissions. Published by BMJ.

Faculty of Economics,

Management and Accountancy, University of Malta, Msida, Malta

\section{Correspondence to}

Dr Jonathan Spiteri;

jonathan.v.spiteri@um.edu.mt

\section{ABSTRACT}

The role of the media as a source of reliable health information during the COVID-19 pandemic has come under intense scrutiny, with claims of misinformation and partisanship coming from all sides of the political divide. This paper seeks to understand the relationship between exposure to biased media outlets and the likelihood of testing positive for COVID-19 in the USA. I use detailed household data extracted from the 2020 American National Election Study in order to gauge media consumption patterns, coupled with data on media bias scores for different outlets and programmes. I combine these variables to compute media bias exposure values for each respondent, and relate these to the likelihood of a positive COVID-19 test within each respondent's household, controlling for a variety of other factors including partisanship, social media use, trust in the media and several socioeconomic and demographic variables. The results indicate that media bias exposure is significantly related to COVID-19 incidence, and in particular the coefficients show that a $1 \%$ increase in exposure to left-wing media is associated with a $0.2 \%$ decrease in the probability of a positive COVID-19 test. Conversely, I find no significant relationship between right-wing media exposure and COVID-19 infection rates. I also find a significantly higher likelihood of contracting COVID-19 among low socioeconomic status households, suggesting a disproportionate impact of the pandemic on such cohorts. These findings are robust to a number of tests, and emphasise the importance of aligning media messages with those advocated by leading medical experts during public health crises.

\section{INTRODUCTION}

The global outbreak of COVID-19 has profoundly impacted social, economic and institutional structures, with implications that are likely to resonate for many years to come. Apart from the significant death toll, with almost 4 million deaths worldwide within 17 months of its initial outbreak, ${ }^{1}$ the pandemic has led to staggering levels of hospitalisations and intensive care treatment, ${ }^{2}$ placing considerable strain on healthcare resources across the globe.

All of this turmoil has been played out in vivid detail across all forms of news media, which itself has been subject to significant

\section{WHAT IS ALREADY KNOWN? \\ $\Rightarrow$ COVID-19 has had a significant impact on human health across the globe. \\ $\Rightarrow$ Media reportage in the USA is highly polarised across the partisan divide, with such practices also visible in relation to the COVID-19 pandemic. \\ WHAT ARE THE NEW FINDINGS? \\ $\Rightarrow$ Exposure to left-leaning news media, across sever- al different platforms and programmes (particular- ly online news portals), is associated with a lower probability of contracting COVID-19 in the USA. \\ $\Rightarrow$ By contrast, there is no significant relationship be- tween right-wing exposure and the likelihood of a positive COVID-19 test. \\ WHAT DO THE NEW FINDINGS IMPLY? \\ $\Rightarrow$ The media continues to play a crucial role in the transmission of health information during public health crises. \\ $\Rightarrow$ The alignment of media messages with those advo- cated by medical experts, without any attempt at po- litical slant, is crucial in the battle against the spread of COVID-19 and future pandemics.}

upheaval in recent years. More specifically, the rise of online news portals and social media has completely altered the nature of the traditional media landscape, while the inexorable reality of 'fake news' and biased reportage has called into question the reliability of the news media. ${ }^{3} 4$ In fact, the most recent Edelman Trust Barometer reports that only $46 \%$ of Americans trust traditional media, the first time that this value has dipped below half. ${ }^{5}$

The aim of this paper is to understand whether the likelihood of a positive COVID-19 diagnosis is associated with the partisan leaning of the various news media consumed by the individual in question. To this end, I use the 2020 American National Election Study (ANES) covering a sample of 8280 respondents, and which includes detailed information on respondents' media consumption habits across several outlets and platforms. I combine the latter with quantitative scores for partisanship media bias in order to characterise both 
the quantity and political slant of respondents' media exposure. In turn, I relate individual media exposure to data on whether respondents have ever tested positive for COVID-19, also derived from the 2020 ANES, controlling for several other potential covariates and socioeconomic variables.

This paper fits in with the growing literature on the influence of the media on public health. Several studies have shown that media communication of health information can have significant positive impacts in terms of encouraging the use of appropriate healthcare services and tests, as well as the increased uptake of protective behaviour. ${ }^{6-8}$ Although it is clear that the media can have a positive impact in terms of promoting desirable health behaviour, some downsides exist, particularly if the media provides conflicting information that may confuse individuals, or potentially create fatalistic beliefs regarding their health status. ${ }^{9-11}$

Another strand of the literature considers the role of the media within the context of an infectious disease outbreak or pandemic. Some authors have underlined the positive role of the media in helping to delay outbreaks and decreasing their severity as a result of the relevant health information transmitted to citizens. ${ }^{12} 13$ Nonetheless, the COVID-19 pandemic has raised several important questions regarding the role of the media in society, with some finding that online media assisted in the spread of misinformation regarding the pandemic worldwide, which in turn may hinder public health officials in managing the outbreak. ${ }^{14}$ More specifically, the type and extent of COVID-19-related coverage may depend on the partisan or political slant of the media outlet in question. ${ }^{15}$ Within this context, a burgeoning literature has sought to understand the impact of such reportage on health behaviours and outcomes during the pandemic. In particular, recent studies show that exposure to Fox News is associated with a lower propensity to engage in social distancing and other protective practices like using hand sanitisers or wearing masks. ${ }^{16}{ }^{17}$ Similarly, others find a significant divergence in both preventative and risky behaviours related to the spread of COVID-19 across people who trust Fox News and those who trust CNN, with both outlets lying at different ends of the partisan spectrum. ${ }^{18}$

This paper contributes to this growing literature in a number of ways. First, I consider the relationship between exposure to different media outlets and the likelihood of testing positive for COVID-19, thus focusing on health outcomes rather than preventative or risky behaviours. I also consider a much wider gamut of media sources, across different programmes, platforms and partisanship slant, thus enabling me to capture a more holistic picture of people's media consumption habits and a more nuanced assessment of exposure to bias. Finally, the richness of the ANES dataset also allows me to control for several potential confounders, including awareness of COVID-19 symptoms, perceptions regarding the government's COVID-19 response and individual partisanship.
METHODS

\section{Econometric model}

In this section, I specify the econometric model to be estimated in order to capture the relationship between media bias exposure and the incidence of COVID-19, together with the key explanatory variable of interest. The model can be expressed as follows:

$$
\operatorname{COVID}_{i}=\alpha_{0}+\beta_{1} M B E_{i}^{L}+\beta_{2} M B E_{i}^{R}+\Pi X_{i}+\varepsilon_{i}
$$

Where:

$\mathrm{COVID}_{i}=$ self-reported incidence of someone within respondent $i$ 's household testing positive for COVID-19.

$M B E_{i}^{L}=\mathrm{a}$ measure of left-wing media bias exposure for respondent $i$.

$M B E_{i}^{R}=$ a measure of right-wing media bias exposure for respondent $i$.

$X_{i}=$ vector of other covariates and controls.

$\varepsilon_{i}=$ random disturbance term.

As discussed above, one of the key features of this paper is its focus on media exposure across a wide variety of platforms, types and biases. Given that the political bias of the media consumed is a potentially important determinant of COVID-19 incidence, I define the extent of media bias exposure $\left(M B E_{i}^{s}\right)$ as follows:

$$
M B E_{i}^{s}=\sum_{i} \sum_{k} C_{i, k}^{s} B_{k}^{s}
$$

Where $C_{i, k}^{s}$ is a dummy variable that captures individual $i$ 's consumption of media outlet $k$ with partisan slant $s\left(s \in\{L, R\} ; C_{i, k} \in\{0,1\}\right)$, while $B_{k}^{s}$ is a quantitative measure of media outlet $k$ 's level of left-wing or rightwing political bias, such that $B_{k}^{s}>0$. Thus, highly partisan media consumption patterns will result in high values for $M B E_{i}^{s}$, while low levels of partisanship across the political spectrum will result in low values for $M B E_{i}^{s}$. It is imperative to note that this latter category would also include individuals who consume little or no media (irrespective of bias), as well as those who only consume relatively unbiased news. This set-up enables me to capture the separate, differential effect of both right-wing and leftwing media exposure on the likelihood of a positive COVID-19 test.

\section{Data and estimation}

The main data source for estimating equation (1) is the 2020 ANES. $^{19}$ The ANES is a wide-ranging survey conducted jointly by Stanford University and the University of Michigan since 1948, funded by a National Science Foundation grant, aimed at understanding the perceptions, motivating factors and voting behaviours of American citizens for each US presidential election. Often referred to as the 'gold standard' of public opinion surveys,${ }^{20}$ the 2020 ANES survey includes 8280 respondents, representative of the communitydwelling US electorate (population aged 18 years and over), and was conducted over the period 18 August 2021-3 November 2021. The survey covers typical topics including voting intentions and partisanship, opinions regarding a number of salient issues as well as COVID19-specific questions given the unique circumstances 
surrounding the 2020 election, including whether any person within the respondent's household had tested positive for COVID-19, which is the dependent variable in equation (1). One potential concern might be that since the survey was administered to respondents at different points in time over a 3-month period, the timing of the actual response may have influenced the likelihood of a positive COVID-19 test since the number of positive cases nationwide increased over this time period. However, it is important to note that the choice of when to administer the survey to respondents was done independently of their voting intentions, partisanship, media consumption patterns and socioeconomic status, meaning that the actual timing of the survey is exogenous to our explanatory variables of interest. The survey also includes detailed questions regarding media consumption patterns, covering a wide variety of programmes across TV, radio, print, online newspapers and online news portals, together with social media. More specifically, respondents were provided with a list of 86 of the most popular national programmes and news sources across each of the aforementioned platforms, and asked to select those that they watched, listened to, read or visited (depending on the platform in question) at least once a month. The full list of 64 programmes, radio shows, newspapers and websites used in this paper, together with their respective audience, is provided in online supplemental appendix 1 . When it comes specifically to TV programmes, for the purposes of this paper, I only focus on English-language programmes, given the lack of reliable bias metrics for non-English media (eliminating 16 Spanish TV programmes). I also focus specifically on news programmes or programmes that provide news content in some form, as opposed to purely entertainment programmes like American Idol or NCIS, since the latter would typically not contain any COVID-19related news (eliminating six TV programmes).

Given the specification of media bias exposure in equation (2), a quantitative measure of bias is required for each of the media sources consumed by the respondents. For this purpose, I use the latest media bias scores computed by Ad Fontes Media for each news outlet. ${ }^{21}$ The Ad Fontes Media bias scores, which have been used within the political and public health literature to measure political slant, ${ }^{22}$ assign a score ranging from -42 (extreme left-wing) to 42 (extreme right-wing), with assessments based on various articles or shows that are independently evaluated by at least three analysts spanning the political spectrum. Thus, the final computation for media bias exposure as specified in equation (2) is obtained by noting the absolute value of the relevant media bias score for each of the programmes/outlets listed in online supplemental appendix 1 (and their relative left/right-wing slant), and multiplying it by a dummy variable denoting whether the respondent in question uses that particular media source at least once a month, as recorded in the 2020 ANES survey, and aggregated across all media sources and respondents.

\begin{tabular}{|c|c|c|c|c|}
\hline Variable & Mean & SD & Minimum & Maximum \\
\hline COVID-19 positive test & 0.0351 & 0.1840 & 0 & 1 \\
\hline $\begin{array}{l}\text { Right-wing media bias } \\
\text { exposure }\end{array}$ & 20.2791 & 28.8106 & 0 & 306.02 \\
\hline $\begin{array}{l}\text { Left-wing media bias } \\
\text { exposure }\end{array}$ & 31.2005 & 35.5272 & 0 & 230.21 \\
\hline $\begin{array}{l}\text { Awareness of } \\
\text { COVID-19 symptoms }\end{array}$ & 0.1217 & 0.3270 & 0 & 1 \\
\hline Daily Facebook user & 0.4636 & 0.4987 & 0 & 1 \\
\hline Daily Twitter user & 0.0892 & 0.2851 & 0 & 1 \\
\hline Daily Reddit user & 0.0400 & 0.1959 & 0 & 1 \\
\hline Regular media user & 0.6024 & 0.4894 & 0 & 1 \\
\hline Trust the media & 0.2024 & 0.4018 & 0 & 1 \\
\hline Vote Biden & 0.4555 & 0.4980 & 0 & 1 \\
\hline Male & 0.4554 & 0.4980 & 0 & 1 \\
\hline Hispanic & 0.0920 & 0.2891 & 0 & 1 \\
\hline Non-Hispanic black & 0.0875 & 0.2856 & 0 & 1 \\
\hline Non-Hispanic others & 0.0879 & 0.2831 & 0 & 1 \\
\hline $\begin{array}{l}\text { Non-Hispanic white } \\
\text { (reference category) }\end{array}$ & 0.7237 & 0.4472 & 0 & 1 \\
\hline Income below $\$ 25000$ & 0.1876 & 0.3904 & 0 & 1 \\
\hline $\begin{array}{l}\text { Income } \$ 25000-44 \\
000\end{array}$ & 0.1410 & 0.3481 & 0 & 1 \\
\hline $\begin{array}{l}\text { Income } \$ 45000-69 \\
000\end{array}$ & 0.1564 & 0.3633 & 0 & 1 \\
\hline $\begin{array}{l}\text { Income } \$ 70000-99 \\
000\end{array}$ & 0.1500 & 0.3571 & 0 & 1 \\
\hline $\begin{array}{l}\text { Income } \$ 100000 \\
\text { and over (reference } \\
\text { category) }\end{array}$ & 0.3010 & 0.4587 & 0 & 1 \\
\hline High school dropout & 0.0455 & 0.2083 & 0 & 1 \\
\hline Age 18-24 & 0.0493 & 0.2164 & 0 & 1 \\
\hline Age 25-34 & 0.1501 & 0.3572 & 0 & 1 \\
\hline Age $35-44$ & 0.1660 & 0.3721 & 0 & 1 \\
\hline Age $45-54$ & 0.1463 & 0.3534 & 0 & 1 \\
\hline Age 55-64 & 0.1775 & 0.3821 & 0 & 1 \\
\hline $\begin{array}{l}\text { Age } 65 \text { and over } \\
\text { (reference category) }\end{array}$ & 0.2712 & 0.4446 & 0 & 1 \\
\hline Married & 0.5225 & 0.4995 & 0 & 1 \\
\hline Children 1 or 2 & 0.2408 & 0.4276 & 0 & 1 \\
\hline Children 3 or more & 0.0737 & 0.2613 & 0 & 1 \\
\hline
\end{tabular}

The final sample used in this study consists of 8182 respondents. Data used in this study are unweighted. With the exception of left-wing and right-wing media bias exposure variables, all other variables are binary.

Apart from the main explanatory variable of interest, I also include a number of key covariates and control variables (all coded as binary/dummy variables), exploiting the richness of the ANES dataset, as listed in table 1 . These include typical socioeconomic and demographic variables like gender, age, income bracket, marital status and number of children within the household, with the latter two being of particular importance to control for household size, since the dependent variable relates to the incidence of COVID-19 infection within the 
household, meaning that larger households would be more likely to respond in the affirmative. I also include dummy variables denoting respondents' racial/ethnic groups, namely Hispanics, non-Hispanic black and nonHispanic others (including Asian or Native Hawaiian/ other Pacific Islander, Native American/Alaska Native or other race), with non-Hispanic white as the excluded benchmark category, given the disproportionately high infection rates among Hispanics and other minorities in the USA. ${ }^{23}$ The covariates also include a measure for partisanship, proxied by whether the respondent intended to vote for Joe Biden or not, since political beliefs may be related to both the type of media consumed as well as the incidence of COVID-19, given that as described earlier there are differences across partisan lines in terms of risk preventative measures and attitudes, which may be due to factors beyond media exposure.$^{15}$ I also control for awareness regarding the symptoms associated with COVID-19, since a possible contention might be that divergences in infection rates are related not to political bias per se but rather the provision of tangible information regarding the symptoms of COVID-19, which in turn increase the probability of undertaking a test and obtaining a positive result. I also control for social media use, since a burgeoning literature has pointed towards evidence that social media perpetuates the spread of misinformation and fake news, particularly in relation to COVID-19. ${ }^{24} 25$ Finally, I also account for the extent to which the respondents generally follow and trust in the media, since these may ultimately affect the extent of media bias influence on behaviour.

Table 1 provides summary statistics for the main (unweighted) variables used in this paper for estimating equation (1). A few points are worth noting. First, the final sample used in this study consists of 8182 respondents, with 98 entries deleted due to null responses in relation to the question on COVID-19 incidence within the respondents' household. Second, the rate of positive COVID-19 cases for households within my final sample is $3.5 \%$, which is slightly above the average cumulative infection rate of $2.24 \%$ recorded over the interviewing period among individuals in the USA. ${ }^{26}$ However, it is important to note that the $3.5 \%$ recorded in the survey refers to households rather than individuals, which goes some way to explaining the apparent discrepancy in infection rates, particularly given the extent to which COVID-19 spreads among household members-in some cases with a secondary infection rate of up to $53 \% .{ }^{27}$ Third, the mean aggregate media bias exposure scores indicate that on average, respondents were more likely to report consuming left-leaning media, which tallies with the over-representation of votes for President Joe Biden, who in this sample received $45 \%$ of the vote among the US population over the age of 18 years, above the actual electoral outcome of $39 \%$ of votes. ${ }^{28}$

I use a logistic regression model (Logit) in order to estimate equation (1) given the binary nature of the dependent variable, although very similar results are obtained when using both a linear probability model and a Probit regression model (these are omitted due to space restrictions). Robust SEs are used throughout, to account for heteroskedasticity.

\section{RESULTS}

\section{Main results}

In this section, I present the key results from the Logit estimation of equation (1). The results are presented in table 2, with column 1 showing the results of the bivariate regression while column 2 includes the full set of controls listed in table 1 . Note that for ease of interpretation, the coefficient estimates presented are the average marginal effects across all respondents in the dataset; this presentation style will also be maintained throughout the rest of the paper.

As seen below, both without and with the other explanatory variables, left-wing media bias exposure is negatively and significantly related to the probability of a positive COVID-19 test. In fact, the estimated marginal effects indicate that a $1 \%$ increase in left-wing exposure is linked with a $0.2 \%$ decrease in the likelihood of a positive test. By contrast, no statistically significant relationship is observed between right-wing media bias exposure and the likelihood of a positive test. From a social media standpoint, daily Facebook users are associated with a higher positive test likelihood, while respondents with lower levels of education and younger respondents are all more likely to have reported a positive COVID-19 test, which all indicate that the pandemic has seemingly had a disproportionate impact on low socioeconomic status (SES) households. Hispanics, non-Hispanic black and non-Hispanic others are also more likely to report a positive test, in line with Centers for Disease Control and Prevention (CDC) reports on the disproportionately higher incidence of COVID-19 among minorities. ${ }^{23}$

\section{Results by media type}

I now break down the media bias exposure variable by media type, namely TV, radio, web portals, newspapers and online newspapers, in order to understand the channels through which exposure to bias influences the likelihood of a positive COVID-19 test. The results are shown in table 3 , where in the interest of brevity, I omit the marginal effects for the other covariates, although the regression does include the full suite of explanatory variables reported in table 1.

As seen below, exposure to left-wing web portals exhibits a negative and statistically significant relationship with the likelihood of a positive COVID-19 test, with none of the other left-wing news sources yielding significant results. Thus, it appears that the results observed in table 2 were largely driven by exposure to online news sites including CNN, Huffington Post and The Guardian, among others.

\section{Robustness tests}

I now present a series of additional tests in order to assess the robustness of the findings presented in this paper. 
Table 2 Main results - right-wing and left-wing media bias exposure

\begin{tabular}{|c|c|c|}
\hline Variable & (1) & (2) \\
\hline $\begin{array}{l}\text { Left-wing media bias } \\
\text { exposure }\end{array}$ & $-0.0002^{*}(0.0001)$ & $-0.0002 \dagger(0.0001)$ \\
\hline $\begin{array}{l}\text { Right-wing media } \\
\text { bias exposure }\end{array}$ & $-0.0000(0.0001)$ & $0.0001(0.0001)$ \\
\hline $\begin{array}{l}\text { Awareness of } \\
\text { COVID-19 symptoms }\end{array}$ & - & $0.0905 †(0.0050)$ \\
\hline Daily Facebook user & - & $0.0091^{*}(0.0039)$ \\
\hline Daily Twitter user & - & $0.0038(0.0064)$ \\
\hline Daily Reddit user & - & $0.0023(0.0084)$ \\
\hline Regular media user & - & $-0.0019(0.0043)$ \\
\hline Trust the media & - & $-0.0066(0.0057)$ \\
\hline Vote Biden & - & $-0.0058(0.0044)$ \\
\hline Male & - & $0.0024(0.0039)$ \\
\hline Hispanic & - & $0.031 \dagger(0.0051)$ \\
\hline Non-Hispanic black & - & $0.0349 \dagger(0.0058)$ \\
\hline Non-Hispanic others & - & $0.01345 \ddagger(0.0070)$ \\
\hline $\begin{array}{l}\text { Income below } \$ 25 \\
000\end{array}$ & - & $0.0046(0.0054)$ \\
\hline $\begin{array}{l}\text { Income \$25 000-44 } \\
000\end{array}$ & - & $-0.0083(0.0064)$ \\
\hline $\begin{array}{l}\text { Income } \$ 45 \text { 000-69 } \\
000\end{array}$ & - & $-0.0012(0.0058)$ \\
\hline $\begin{array}{l}\text { Income } \$ 70000-99 \\
000\end{array}$ & - & $-0.0092(0.0060)$ \\
\hline Dropout & - & $0.0164^{*}(0.0081)$ \\
\hline Age 18-24 & - & $0.0171^{*}(0.0086)$ \\
\hline Age 25-34 & - & $-0.0025(0.0069)$ \\
\hline Age $35-44$ & - & $-0.0041(0.0070)$ \\
\hline Age $45-54$ & - & $0.0013(0.0064)$ \\
\hline Age 55-64 & - & 0.0008 (0.0063) \\
\hline Married & - & $0.0028(0.0043)$ \\
\hline Children 1 or 2 & - & $0.0030(0.0046)$ \\
\hline Children 3 or more & - & $0.0012(0.0070)$ \\
\hline $\mathrm{N}$ & 8182 & 8182 \\
\hline Pseudo $\mathrm{R}^{2}$ & 0.0026 & 0.2985 \\
\hline Wald $X^{2}$ & $5.00 \ddagger$ & $663.22 \dagger$ \\
\hline
\end{tabular}

The coefficients reported are average marginal effects. Robust SEs are shown in parentheses.

${ }^{*}$ Denotes statistical significance at the $5 \%$ level.

†Denotes statistical significance at the $1 \%$ level.

\#Denotes statistical significance at the $10 \%$ level.

In particular, the following tests will tackle issues related to endogeneity between the dependent variable and media bias exposure, prior beliefs as well as an alternative measure of media bias exposure.

I begin with the issue of endogeneity. More specifically, recall that this exposure variable is a function of
Table 3 Results by media type

\begin{tabular}{|c|c|}
\hline Variable & (1) \\
\hline Left-wing TV media bias exposure & $0.0001(0.0001)$ \\
\hline Left-wing radio media bias exposure & $-0.0005(0.0006)$ \\
\hline Left-wing web media bias exposure & $-0.0003^{*}(0.0001)$ \\
\hline $\begin{array}{l}\text { Left-wing newspaper media bias } \\
\text { exposure }\end{array}$ & $0.0001(0.0007)$ \\
\hline Left-wing online media bias exposure & $-0.0007(0.0005)$ \\
\hline Right-wing TV media bias exposure & $-0.0000(0.0052)$ \\
\hline Right-wing radio media bias exposure & $0.0001(0.0001)$ \\
\hline Right-wing web media bias exposure & $-0.0000(0.0003)$ \\
\hline $\begin{array}{l}\text { Right-wing newspaper media bias } \\
\text { exposure }\end{array}$ & $-0.0066(0.0040)$ \\
\hline Right-wing online media bias exposure & $0.0013(0.0021)$ \\
\hline $\mathrm{N}$ & 8182 \\
\hline Pseudo $\mathrm{R}^{2}$ & 0.3031 \\
\hline Wald $X^{2}$ & $672.24 \dagger$ \\
\hline \multicolumn{2}{|c|}{$\begin{array}{l}\text { The coefficients reported are average marginal effects. Robust SEs } \\
\text { are shown in parentheses. All of the covariates listed in table } 1 \\
\text { have been included in the regression. } \\
\text { *Denotes statistical significance at the } 5 \% \text { level. } \\
\text { †Denotes statistical significance at the } 1 \% \text { level. } \\
\text { †Denotes statistical significance at the } 10 \% \text { level. }\end{array}$} \\
\hline
\end{tabular}

both media consumption as well as the slant or bias of the media outlet in question. It is possible that reverse causality may exist between COVID-19 incidence and both elements of the media bias exposure variables specified in this paper, namely the amount of news consumed by the respondent and the choice of media outlets. In the first instance, the incidence of COVID-19 within a household may have prompted the respondent to seek out more information about the virus from the media, resulting in higher levels of consumption, which in turn influences the extent of media bias exposure. Thus, to account for this potential source of endogeneity I rerun equation (1), this time focusing specifically on the mean media bias that each respondent was reportedly exposed to, effectively eliminating the extent of media consumption. This is done by dividing the media bias exposure values derived above by the quantity of different media consumed by each respondent, obtaining an average media bias score per news programme/site, for both right-wing and left-wing media. The results are shown in table 4 column 1, where the marginal effects for all of the covariates listed in table 1 are omitted. As seen below, once again I observe a negative and statistically significant relationship between mean left-wing media bias and the probability of a positive COVID-19 test, which suggests that the results obtained earlier were not driven by endogeneity issues related to media consumption.

The second source of potential endogeneity relates to the choice of media outlets, and thus the extent of bias. It is plausible that upon receiving a positive COVID-19 
Table 4 Robustness tests-endogeneity and prior COVID-19 beliefs

\begin{tabular}{|c|c|c|}
\hline Variable & (1) & (2) \\
\hline Left-wing mean bias & $-0.0009^{*}(0.0004)$ & $-0.0008^{*}(0.0004)$ \\
\hline Right-wing mean bias & $0.0003(0.0003)$ & $0.0002(0.0003)$ \\
\hline $\begin{array}{l}\text { Lax COVID-19 } \\
\text { restrictions }\end{array}$ & - & $-0.0057(0.0042)$ \\
\hline $\begin{array}{l}\text { Hydroxychloroquine } \\
\text { is effective }\end{array}$ & - & $0.0064(0.0047)$ \\
\hline $\begin{array}{l}\text { COVID-19 developed } \\
\text { in lab }\end{array}$ & - & $0.0019(0.0041)$ \\
\hline $\mathrm{N}$ & 8182 & 8182 \\
\hline Pseudo $\mathrm{R}^{2}$ & 0.2976 & 0.2996 \\
\hline Wald $X^{2}$ & 659.64† & $675.79 \dagger$ \\
\hline \multicolumn{3}{|c|}{$\begin{array}{l}\text { The coefficients reported are average marginal effects. Robust } \\
\text { SEs are shown in parentheses. All of the covariates listed in } \\
\text { table } 1 \text { have been included in the regression. } \\
{ }^{*} \text { Denotes statistical significance at the } 5 \% \text { level. } \\
\text { †Denotes statistical significance at the } 1 \% \text { level. } \\
\text { fDenotes statistical significance at the } 10 \% \text { level. }\end{array}$} \\
\hline
\end{tabular}

test result within their household, the respondent in question sought out specific sources of news, irrespective of their partisanship. A priori it is not entirely clear what media choices would have been made in this case; the respondent could have picked left-wing media for their greater focus on the recommendations and views of health experts, ${ }^{18}$ or else more right-leaning media due to their efforts aimed at downplaying the risks posed by the virus, ${ }^{16}$ and stories that are not in line with medical health experts. ${ }^{29}$ Therefore, to account for this potential confounding issue, I include a number of variables related to the respondents' beliefs regarding the pandemic, and which were (and to some extent still are) associated with prime news stories that were covered differently across the political spectrum. Specifically, I include a variable denoting whether the respondent believes that COVID-19 restrictions at the time of the survey were too lax or not; another variable denoting whether the respondent believes that hydroxychloroquine is a safe and effective treatment against COVID-19; and finally, a variable denoting whether the respondent believes that COVID-19 was intentionally developed in a laboratory or not. The idea is to assess whether the significant results obtained earlier are being driven by this desire for biased information related to the pandemic or not. This test also serves to further control for pre-existing respondent beliefs related to the pandemic, which may be exogenous to their own partisanship but which may nonetheless inform both their media bias exposure (related to confirmation bias $^{30}$ ), and the likelihood of contracting the virus.

The results are shown in table 4 column 2 . Once again, left-wing media bias exposure is negatively and significantly related to the probability of a positive COVID-19 test, with the marginal effect almost identical to that obtained in column 1. Therefore, this further underscores the strength of the relationship between media bias exposure and COVID-19 incidence, even after accounting for potential endogeneity.

The third robustness test takes a deeper look at the issue of partisanship. More specifically, it is possible that individual partisan leanings may influence both the choice of media outlets and programmes, as well as broader behaviours which may in turn affect the likelihood of contracting COVID-19. To some extent, this has already been controlled for via two avenues, namely the covariate denoting voting intentions for Joe Biden as well as the previous robustness tests where I included a set of variables related to COVID-19 beliefs. Nonetheless, it is clear that voting intentions may not adequately reflect the partisanship or indeed the political values of respondents, and may simply reflect their individual preference for one candidate over the other. Therefore, it makes sense to control for the partisan leanings of respondents directly in the regression model, beyond simply voting intentions or indeed COVID-19 perceptions as done in the robustness tests. The 2020 ANES contains a separate question on the partisanship of the respondent, on a 7-point scale ranging from extremely liberal (1) to extremely conservative (7). Using these data, I create two dummy variables-one denoting whether the respondent identifies as a liberal (scale score from 1 to 3 ) and another one to denote whether they identify as a conservative (scale score from 5 to 7 ). I include these two new variables in equation (1), and rerun the logistic regression from table 2 with all covariates.

The results are shown in table 5 column 1 . Once again, left-wing media bias exposure is negatively

Table 5 Robustness tests - partisanship and alternative measure of media bias

\begin{tabular}{lll}
\hline Variable & (1) & (2) \\
\hline $\begin{array}{l}\text { Left-wing media bias } \\
\text { exposure-Ad Fontes }\end{array}$ & $-0.0002^{\star}(0.0001)$ & - \\
\hline $\begin{array}{l}\text { Right-wing media bias } \\
\text { exposure -Ad Fontes }\end{array}$ & $0.0000(0.0001)$ & - \\
\hline $\begin{array}{l}\text { Left-wing media bias } \\
\text { exposure-AllSides }\end{array}$ & - & $-0.0011^{*}(0.0005)$ \\
\hline $\begin{array}{l}\text { Right-wing media bias } \\
\text { exposure-AllSides }\end{array}$ & - & $0.0005(0.0007)$ \\
\hline Conservative & $-0.0006(0.0049)$ & \\
\hline $\begin{array}{l}\text { Liberal } \\
\mathrm{N}\end{array}$ & $-0.0067(0.0053)$ & \\
\hline Pseudo $\mathrm{R}^{2}$ & 8182 & 8182 \\
\hline Wald $\mathrm{X}^{2}$ & 0.2993 & 0.2978 \\
\hline
\end{tabular}

The coefficients reported are average marginal effects. Robust SEs are shown in parentheses. All of the covariates listed in table 1 have been included in the regression. ${ }^{*}$ Denotes statistical significance at the $5 \%$ level. †Denotes statistical significance at the $1 \%$ level. ¥Denotes statistical significance at the $10 \%$ level. 
and significantly related to the likelihood of a positive COVID-19 test, with the marginal effects obtained extremely similar to those obtained for the whole sample in table 2. Being a liberal is negatively and significantly correlated (at the $10 \%$ level) with the probability of a positive COVID-19 test, which does suggest that liberals are generally less likely to contract COVID-19 due to their inherent actions and behaviours, but nonetheless this does not in any way erode the explanatory power of media bias exposure.

The final robustness test tackles the issue of media bias measurement. In this paper, I have used the Ad Fontes Media metric for assessing the partisan bias of media outlets and programmes, given its common usage within the literature as cited earlier. Nonetheless, this measure has received some criticism related to the rigour of the methodology used, and in particular its reliance on a small number of stories or articles in order to assess biasedness. ${ }^{31}$ Therefore, in order to address these potential pitfalls, I use an alternative measure of media bias developed by AllSides, ${ }^{32}$ which has also been used within the literature. ${ }^{33}$ This metric classifies over 800 media outlets, programmes and personalities into five categories of political bias, namely 'Left', 'Lean Left', 'Centre', 'Lean Right' and 'Right', using a variety of methods like blind surveys, analysis conducted by third parties (eg, academics, etc) and editorial reviews. For the purposes of this study, I recode the bias scores on a scale from 0 to 2 for left-wing and right-wing outlets separately. I then rerun equation (2) in order to assess the relationship between media bias exposure and the incidence of COVID-19 using this new measure of bias.

The results are shown in table 5 column 2. Once again, all covariates are included in both regressions, although the marginal effects are omitted for conciseness. As seen above, left-wing media bias exposure is once again negatively and significantly related to the likelihood of a positive COVID-19 test. In fact, the marginal effects obtained show that a $1 \%$ increase in exposure to left-wing media outlets is consistent with a $0.16 \%$ decline in the probability of a positive COVID-19 test, which is markedly similar to the result obtained in table 2 using the Ad Fontes Media bias score. Thus, these findings provide further evidence of the robust nature of the relationship between left-wing media bias exposure and COVID-19 incidence.

\section{DISCUSSION}

This paper has sought to analyse the relationship between media bias exposure and the incidence of COVID-19. Specifically, my aim was to understand whether consumption of politically biased news outlets across the entire left-right spectrum is associated with the probability of testing positive for COVID-19. The results showed that left-wing media bias exposure is negatively and significantly related to the likelihood of a positive COVID-19 test. Moreover, this relationship is primarily driven by exposure to online left-wing news outlets, underscoring the ever-growing importance of online news sources, not simply in terms of their increased readership but also their influence on people's behaviour and attitudes, ${ }^{34}$ at least in relation to health and the pandemic. By contrast, I found no significant relationship between exposure to right-wing media and virus incidence. In addition, the likelihood of testing positive for COVID-19 was positively related to daily social media usage (specifically Facebook), echoing other findings cited earlier on the rapid and substantial spread of COVID-19 misinformation via social media. ${ }^{24}{ }^{25}$ Furthermore, having dropped out of high school, and being within the 18-24 age bracket are also associated with a higher probability of testing positive, confirming initial findings based on the impact of past pandemics, ${ }^{35}$ which perpetuated existing inequality levels due to a variety of factors like job losses and unequal access to medical services. In addition, Hispanics, nonHispanic black and non-Hispanic others are also significantly more likely to report a positive COVID-19 test relative to non-Hispanic white, highlighting the extent to which the pandemic has disproportionately impacted minorities within the USA, which also led to higher levels of hospitalisation within these communities. ${ }^{36}$

The findings in this paper differ from the literature, ${ }^{1617}$ in that there is no significant relationship between rightwing media exposure and the likelihood of a positive COVID-19 test. This divergence may be due to several factors. First, the other studies focus on attitudes and self-reported behaviours, whereas this paper focuses on COVID-19 incidence; although the two are related, it is possible that some actions are more effective than others in terms of warding off the disease. ${ }^{37}$ It is also possible that self-reported protective or risky behaviours differ from actual ones, with a long, well-established literature underscoring that significant gaps may exist in this regard..$^{38} 39$ Furthermore, it is important to note that while the other studies focus solely on Fox News, this paper comprises several other media outlets along the political spectrum in an attempt at obtaining a more nuanced perspective on media bias exposure, since I include several different right-wing and left-wing outlets. The fact that this paper includes a variety of right-wing outlets and programmes (sometimes from the same outlet) may also contribute to this discrepancy, since although the outlets are right wing, evidence suggests that there may be significant variation across the different outlets and programmes, both in terms of partisanship and more importantly the way in which the COVID-19 pandemic was presented to viewers. ${ }^{40}$ Hence, the lack of significant results observed for right-wing media exposure may be due to the diversity of COVID-19 reportage among right-wing news outlets and programmes. Nonetheless, the findings in this paper align somewhat with others, ${ }^{18}$ who find that people who trust CNN exhibit a greater tendency towards protective behaviours and a lower tendency towards risky behaviours relative to those who trust Fox News. Unlike the divergences in reportage among right-wing media discussed earlier, in this case the evidence indicates that 
left-leaning news outlets across the board closely report the information and advice issued by medical experts and public health officials in the USA. ${ }^{41}$ Therefore, the results obtained in this paper may in part reflect this general adherence of left-wing media to the health communications and information provided by public health officials.

The findings from this paper raise a number of key points in relation to the news media and the COVID-19 pandemic. First, the results emphasise the importance of adhering to health information and opinions provided by recognised medical experts in the reportage of news related to health, and in this case the pandemic itself, since as mentioned earlier this was a feature of leftleaning news outlets' reporting on COVID-19. ${ }^{40}$ As mentioned above, the findings from the Logit regressions indicate that a $1 \%$ increase in left-wing media bias exposure is consistent with a $0.2 \%$ drop in the probability of a positive COVID-19 test. If we extrapolate this to the entire US population, this would translate to a decrease of almost 18500 positive COVID-19 cases (cumulative) as of 3 November 2020, and the prevention of around 370 COVID-19 deaths on average ${ }^{26}$ with a disproportionate number of those cases prevented and lives saved within minority populations. Therefore, media reportage of medical facts can have tangible impact in terms of reducing infection rates and ultimately saving lives during health emergencies such as the COVID-19 pandemic.

Apart from the obvious human aspect, such reductions also have clear economic benefits, since the healthcare costs related to uninsured hospitalisation from COVID-19 in the USA range from US\$51 389 for patients aged 21-40 years old, to US\$78 569 for patients aged 41-60 years old. ${ }^{42}$ This particular point is closely related to the findings on the disproportionate incidence of the virus on low SES households, many of whom do not have private health insurance. ${ }^{43}$ As mentioned earlier, this higher level of COVID-19 incidence among these cohorts is likely to propagate existing inequalities, particularly since low SES households may struggle to afford the necessary healthcare costs associated with COVID-19 hospitalisation, resulting in both short-term and longerterm work absences due to poor health, and therefore lower incomes. ${ }^{44}$ Thus, these findings further contribute to the debate on widening access to high-quality healthcare services across all socioeconomic groups in order to curtail rising inequalities exacerbated by the COVID-19 pandemic.

This study has a number of limitations. First, the use of cross-sectional as opposed to time-varying panel or experimental data means that the findings described above cannot be considered as causal in nature, despite efforts aimed at controlling for several potential confounders, partisanship and endogeneity. Second, although the study covers a large number of news outlets, the selection is limited to national-level media sources, with no focus on more state-level or local media, due to data limitations. Although it is likely that the partisan bias of respondents' national media choices also reflects those of their local consumption patterns, this is nonetheless a shortcoming, particularly where local media outlets are limited both in number and in partisan diversity. Third, although I use two different measures of media bias, I do not directly observe the actual reportage on COVID-19 of each news outlet or indeed whether respondents consumed such news or not.

\section{CONCLUSION}

In conclusion, this paper has underlined the pervasive influence of the media, in this case within the context of the likelihood of contracting COVID-19. This comes despite growing criticism and record low levels of trust in the media among the general public within the USA. ${ }^{5}$ Predictably, the media's reporting on the COVID-19 pandemic has also been subject to significant scrutiny from all sides of the political aisle, particularly in the USA, with several pointing towards the polarised nature of coverage based on partisanship and political bias. ${ }^{45}$ This paper contributes to this debate by showing how exposure to left-leaning media is consistently associated with a lower probability of testing positive for COVID-19, with such outlets generally aligning their health messaging to those promulgated by independent health experts and knowledge. This only serves to emphasise that when it comes to health-related communications, political spin or partisanship should be eschewed completely, with consistent, factual reportage across all media platforms helping in delivering a consistent message that would ultimately assist in greater transmission of vital knowledge with significant implications for health and human life.

Contributors JS is the sole author of this work.

Funding The authors have not declared a specific grant for this research from any funding agency in the public, commercial or not-for-profit sectors.

Competing interests None declared.

Patient consent for publication Not required.

Provenance and peer review Not commissioned; externally peer reviewed.

Data availability statement Data may be obtained from a third party and are not publicly available. The ANES 2020 data are available from the American National Elections Studies website: https://electionstudies.org/data-center/2020-timeseries-study/ . Data on media bias scores may be acquired from the Ad Fontes Media website: https://www.adfontesmedia.com/.

Supplemental material This content has been supplied by the author(s). It has not been vetted by BMJ Publishing Group Limited (BMJ) and may not have been peer-reviewed. Any opinions or recommendations discussed are solely those of the author(s) and are not endorsed by BMJ. BMJ disclaims all liability and responsibility arising from any reliance placed on the content. Where the content includes any translated material, BMJ does not warrant the accuracy and reliability of the translations (including but not limited to local regulations, clinical guidelines, terminology, drug names and drug dosages), and is not responsible for any error and/or omissions arising from translation and adaptation or otherwise.

Open access This is an open access article distributed in accordance with the Creative Commons Attribution Non Commercial (CC BY-NC 4.0) license, which permits others to distribute, remix, adapt, build upon this work non-commercially, and license their derivative works on different terms, provided the original work is properly cited, appropriate credit is given, any changes made indicated, and the use is non-commercial. See: http://creativecommons.org/licenses/by-nc/4.0/.

\section{REFERENCES}

1 World Health Organization. Who coronavirus (COVID-19) Dashboard Available: https://covid19.who.int/ [Accessed 31 May 2021]. 
2 Roser M, Ritchie H, Ortiz-Ospina E. Coronavirus pandemic (COVID-19), 2020. Available: https://ourworldindata.org/coronavirus

3 Lazer DMJ, Baum MA, Benkler Y, et al. The science of fake news. Science 2018;359:1094-6.

4 van der Meer TGLA, Hameleers M. Fighting biased news diets: using news media literacy interventions to stimulate online cross-cutting media exposure patterns. New Media Soc 2020;1461444820946455: 146144482094645.

5 Edelman. Edelman Trust Barometer, 2021. Available: https://www. edelman.com/trust/2021-trust-barometer [Accessed 18 May 2021].

6 Jaramillo $E$. The impact of media-based health education on tuberculosis diagnosis in Cali, Colombia. Health Policy Plan 2001;16:68-73.

7 Grilli R, Ramsay C, Minozzi S. Mass media interventions: effects on health services utilisation. Cochrane Database Syst Rev 2002;1:CD000389.

8 Bowen HL. Impact of a mass media campaign on bed net use in Cameroon. Malar J 2013;12:1-8.

9 Nagler RH. Adverse outcomes associated with media exposure to contradictory nutrition messages. J Health Commun 2014;19:24-40.

10 Niederdeppe J, Lee T, Robbins R, et al. Content and effects of news stories about uncertain cancer causes and preventive behaviors. Health Commun 2014;29:332-46.

$11 \mathrm{Im} \mathrm{H}$, Huh J. Does health information in mass media help or hurt patients? investigation of potential negative influence of mass media health information on patients' beliefs and medication regimen adherence. J Health Commun 2017;22:214-22.

12 Xiao Y, Tang S, Wu J. Media impact switching surface during an infectious disease outbreak. Sci Rep 2015;5:1-9.

13 Yan Q, Tang S, Gabriele S, et al. Media coverage and hospital notifications: correlation analysis and optimal media impact duration to manage a pandemic. J Theor Biol 2016;390:1-13.

$14 \mathrm{Li} \mathrm{HO}-\mathrm{Y}$, Bailey A, Huynh D, et al. Youtube as a source of information on COVID-19: a pandemic of misinformation? BMJ Glob Health 2020;5:e002604.

15 Allcott H, Boxell L, Conway J, et al. Polarization and public health: partisan differences in social distancing during the coronavirus pandemic. J Public Econ 2020;191:104254.

16 Ash E, Galletta S, Hangartner D. The effect of Fox news on health behavior during COVID-19. SSRN J 2020;3636762.

17 Simonov A, Sacher SK, Dubé JP. The persuasive effect of Fox news: non-compliance with social distancing during the covid-19 pandemic. National Bureau of Economic Research, 2020.

18 Zhao E, Wu Q, Crimmins EM, et al. Media trust and infection mitigating behaviours during the COVID-19 pandemic in the USA. BMJ Glob Health 2020;5:e003323.

19 American National Election Studies. ANES 2020 Time Series Study Preliminary Release: Combined Pre-Election and Post-Election Data [dataset and documentation], 2021. Available: www.electionstudies. org [Accessed 04 May 2021].

20 Aldrich JH, McGraw KM, eds. Improving public opinion surveys: interdisciplinary innovation and the American national election studies. Princeton, NJ, USA: Princeton University Press, 2012.

21 Ad Fontes media. The media bias chart version 7.0, 2021. Available: https://www.adfontesmedia.com/static-mbc/?v=402f03a963ba [Accessed 07 May 2021].

22 Christensen SR, Pilling EB, Eyring JB, et al. Political and personal reactions to COVID-19 during initial weeks of social distancing in the United States. PLoS One 2020;15:e0239693.

23 Centers for Disease Control and Prevention. Demographic trends of COVID-19 cases and deaths in the US reported to CDC. Available: https://covid.cdc.gov/covid-data-tracker/\#demographics [Accessed 27 Jul 2021].
24 Ayers JW, Chu B, Zhu Z, et al. Spread of misinformation about face masks and COVID-19 by automated software on Facebook. JAMA Intern Med 2021. doi:10.1001/jamainternmed.2021.2498. [Epub ahead of print: 07 Jun 2021].

25 Obiała J, Obiała K, Mańczak M, et al. COVID-19 misinformation: accuracy of articles about coronavirus prevention mostly shared on social media. Health Policy Technol 2021:10:182-6.

26 Centers for Disease Control and Prevention. COVID Data Tracker Weekly Review, 2020. Available: https://www.cdc.gov/coronavirus/ 2019-ncov/covid-data/covidview/index.html [Accessed 15 May 2021].

27 Grijalva CG, Rolfes MA, Zhu Y, et al. Transmission of SARS-COV-2 Infections in Households - Tennessee and Wisconsin, AprilSeptember 2020. MMWR Morb Mortal Wkly Rep 2020;69:1631-4.

28 Federal Election Commission. Official 2020 presidential General election results. Available: https://www.fec.gov/resources/cmscontent/documents/2020presgeresults.pdf [Accessed 17 May 2021]

29 Stecula DA, Pickup M. How populism and conservative media fuel conspiracy beliefs about COVID-19 and what it means for COVID-19 behaviors. Research \& Politics 2021;8:205316802199397.

30 Ling R. Confirmation bias in the era of mobile news consumption: the social and psychological dimensions. Digit J 2020;8:596-604.

31 Wilner T. We can probably measure media bias. but do we want to? Columbia journalism review, 2018. Available: https://www.cj.org/ innovations/measure-media-bias-partisan.php [Accessed 16 May 2021].

32 AllSides. How AllSides rates media bias: our methods. Available: https://www.allsides.com/media-bias/media-bias-rating-methods [Accessed 07 May 2021].

33 Krieg SJ, Schnur JJ, Marshall JD. Pandemic pulse: unraveling and modeling social signals during the COVID-19 pandemic. DGOV 2020;2:1-9.

34 Allan S. Online news: journalism and the Internet: journalism and the Internet. London, UK: McGraw-Hill Education, 2006.

35 Furceri D, Loungani P, Ostry JD. Will Covid-19 affect inequality? Evidence from past pandemics. Covid Economics 2020;12:138-57.

36 Trick WE, Badri S, Doshi K, et al. Epidemiology of COVID-19 vs. influenza: differential failure of COVID-19 mitigation among Hispanics, Cook County health, Illinois. PLoS One 2021;16:e0240202

37 Greenstone M, Nigam V. Does social distancing matter? University of Chicago, Becker Friedman Institute for economics working paper No. 2020-26. SSRN Electronic J.

38 Lichtman SW, Pisarska K, Berman ER, et al. Discrepancy between self-reported and actual caloric intake and exercise in obese subjects. N Engl J Med 1992;327:1893-8.

39 Brener ND, Billy JOG, Grady WR. Assessment of factors affecting the validity of self-reported health-risk behavior among adolescents: evidence from the scientific literature. J Adolesc Health 2003:33:436-57.

40 Bursztyn L, Rao A, Roth CP. Misinformation during a pandemic. National Bureau of Economic Research, 2020.

41 Farias J, Pilati R. COVID-19 as an undesirable political issue: conspiracy beliefs and intolerance of uncertainty predict adhesion to prevention measures. Curr Psychol 2021:1.

42 FAIR Health. Key characteristics of COVID-19 patients, FebruaryAugust 2020. FAIR Health Brief, 2020..

43 Martinez ME, Ward BW. Health care access and utilization among adults aged 18-64, by poverty level: United States, 2013-2015. NCHS Data Brief 2016;262:1-8.

44 Ahmed F, Ahmed Na'eem, Pissarides $\mathrm{C}$, et al. Why inequality could spread COVID-19. Lancet Public Health 2020;5:e240.

45 Hart PS, Chinn S, Soroka S. Politicization and polarization in COVID-19 news coverage. Sci Commun 2020;42:679-97. 